\title{
A 1.5V 20/30 Gb/s CMOS Backplane Driver with Digital Pre-emphasis
}

\author{
Paul Westergaard, Timothy O. Dickson, and Sorin P. Voinigescu \\ ECE Department, University of Toronto, 10 King's College Rd., Toronto, M5S 3G4, Ontario, Canada \\ Email: westerg@eecg.toronto.edu
}

\begin{abstract}
A high-speed input comparator and output driver with adjustable pre-emphasis for applications in serial interchip communications over backplanes at $20 \mathrm{~Gb} / \mathrm{s}$ is presented. The circuit was implemented in 130-nm CMOS and consumes $140 \mathrm{~mW}$ from a $1.5-\mathrm{V}$ supply. It has over $30 \mathrm{~dB}$ dynamic range with a sensitivity of $20 \mathrm{mVp}-\mathrm{p}$ and a differential output swing of $700 \mathrm{mVp}-\mathrm{p}$ at $20 \mathrm{~Gb} /$ $\mathrm{s}$. The output driver features a novel digital pre-emphasis circuit with independent pulse height and width control. Other features include 30\%-70\% eye-crossing control and adjustable output swing between $170 \mathrm{mVp}$ $\mathrm{p}$ and $350 \mathrm{mVp}$-p per side at data rates up to $30 \mathrm{~Gb} / \mathrm{s}$.
\end{abstract}

\section{Introduction}

Serial inter-chip communication is gaining acceptance over parallel architectures mostly because printed circuit board (PCB) routing and pad-limited silicon are excessively costly for commodity designs. To minimize the overall circuit area required for a serial transmitter/ receiver pair, equalization can be performed at the transmitter instead of at the receiver. At the transmitter, preequalizers alter the wave-function to account for the low-pass response of the interconnect. Historically preemphasis has been achieved either using clocked flipflops to first delay the data and then sum it with itself, or with analog differentiators that only allow for amplitude control of the pulse. The flip-flop implementation, while very robust, places severe strain on device technology since the flip-flop operates typically at twice the frequency of the driver istelf. A novel digital differentiator is presented in this paper that enables control of both amplitude and width of the pre-emphasis pulse.

$40 \mathrm{~Gb} / \mathrm{s}$ CMOS amplifiers [1], demultiplexers and multiplexers [2] have been recently reported. While demonstrating the high-speed potential of standard CMOS technology, these circuits suffer from limited dynamic range due to poor sensitivity and due to the modest output swing of about $100 \mathrm{mVp}$-p per side. This paper presents the first CMOS driver with duty-cycle, amplitude, and pre-emphasis control operating with over $30 \mathrm{~dB}$ dynamic range at data rates exceeding 20 Gbps.

\section{Circuit Design}

A. Circuit Topology

Fig.1 shows the block diagram of the backplane driver highlighting the four sections of the circuit. The preemphasis path is placed in parallel with the main signal path and the current from both output stages are summed across the $50 \mathrm{Ohm}$ load resistors (not shown) to develop the differential output voltages. The parallel path consists of delay buffers, and the digital differentiator circuit. The output swing is adjusted from the tail current of the output buffer while the amount of preemphasis is controlled by the tail current of the last stage in the pre-emphasis path.

\section{B. Transistor sizing and biasing for high-speed}

The $\mathrm{f}_{\mathrm{T}}$ and $\mathrm{g}_{\mathrm{m}}$ of a 130-nm n-MOSFET vary linearly with $\mathrm{V}_{\mathrm{GS}}-\mathrm{V}_{\mathrm{T}}$ for effective gate voltages less than $0.25 \mathrm{~V}$ and reach their peak at $0.4 \mathrm{~V}$, corresponding to a drain current density of 0.25 to $0.3 \mathrm{~mA} / \mu \mathrm{m}$. This behaviour is illustrated in Fig. 2. MOS-CML gate voltage swings far exceeding $400 \mathrm{mVp}$-p will therefore lead to unnecessary power dissipation without any improvement in speed. Based on this observation, every circuit block consists of a MOS-CML inverter whose tail current is set to correspond to the peak $f_{T}$ bias of the n-channel MOSFET of $0.25 \mathrm{~mA} / \mu \mathrm{m}$. This bias scheme ensures the maximum switching speed with a voltage swing of $450 \mathrm{mVp}$-p. Inductive peaking is employed in every stage to further improve the bandwidth.

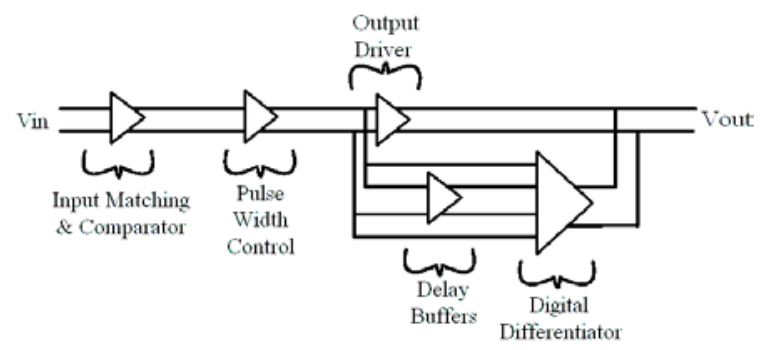

Fig. 1: Backplane driver topology 


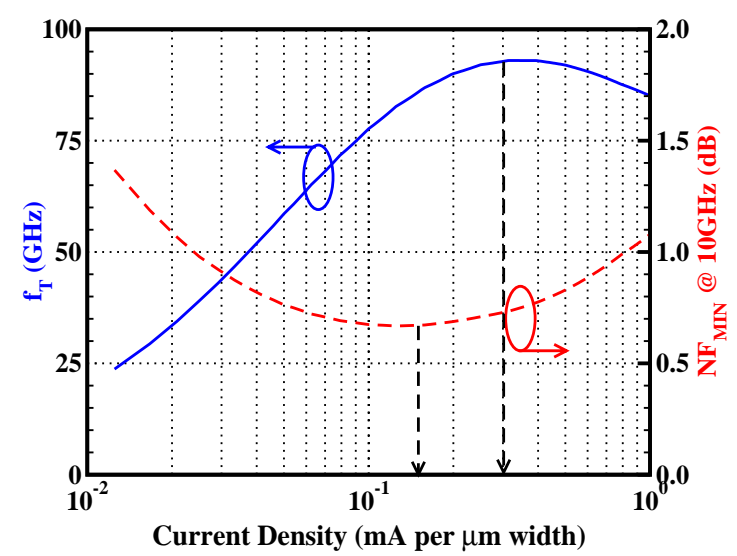

Fig. 2: $\mathrm{f}_{\mathrm{T}}$ and $\mathrm{NF}_{\mathrm{MIN}}$ versus current density for a $130-\mathrm{nm} \mathrm{n}$ MOSFET with $2 \mu \mathrm{m}$ unit finger width biased at $\mathrm{V}_{\mathrm{DS}}=1 \mathrm{~V}$.

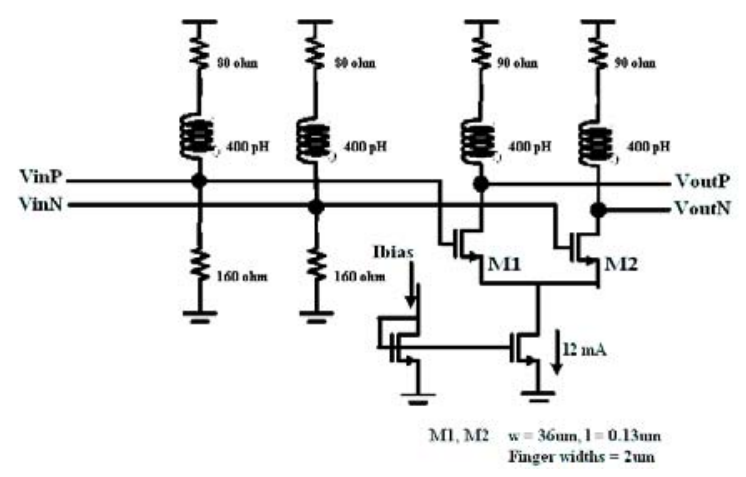

Fig. 3: Input matching network and comparator

\section{Input Matching and Low-noise Comparator}

Fig. 3 shows the input matching network and low-noise comparator. The input differential pair has higher-gain and larger tail current than the other stages in order to reduce the noise. A compromise was reached between achieving the best possible noise match, which calls for large transistor sizes and bias current, and broadband input impedance match. On-chip matching resistors, implemented as a resistive divider with series inductors, provide the gate bias of the input transistors.

\section{Eye-Crossing Control}

The pulse-width control circuit, illustrated in Fig. 4, consists of two inductively-loaded differential stages with a DC offset control pair connected at the output of the first stage. By applying a DC voltage between Vpos and Vneg, an offset voltage is developed on VmidDIFF, shifting the zero-crossing between the two outputs. Due to the finite rise and fall time of the waveform, after truncation by the limiting action of the second inverter, Vout exhibits a change in duty-cycle.

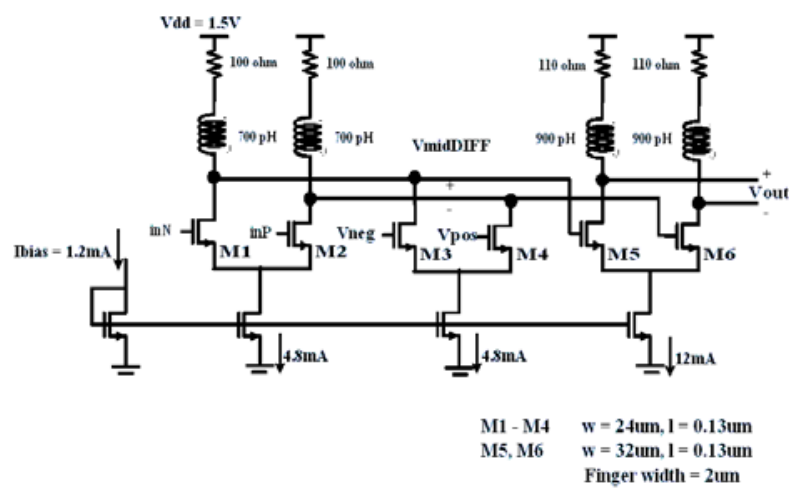

Fig. 4:Pulse-width control circuit and operation

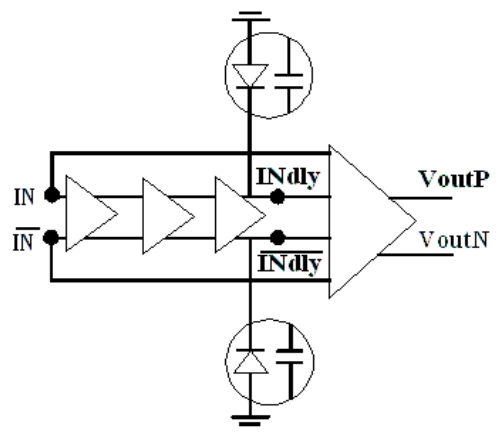

Fig. 5: Digital pre-emphasis block

\section{E. Digital Pre-emphasis}

The digital pre-emphasis circuit whose block diagram is shown in Fig. 5 features three delay cells, implemented as inverters, followed by a digital differentiator circuit. The third delay cell employs varactor diodes connected in parallel with resistive loads in order to control the delay and, therefore, the pre-emphasis spike width.

Fig. 6 illustartes the waveforms in the digital differentiator. The circuit has two differential inputs $I N, \overline{I N}$ and INdly, $\overline{I N d l y}$, and a differential output Voutp, Voutn which is summed with the currents from the main path across the on-chip $50 \Omega$ load resistors.

The logical function is identical to that of a digital XOR gate, with the exception that the output of the digital differentiator operates as a tertiary (three-level) logic system. The pre-ephasis spike height is controlled by two constant current sources Iswch whose value is adjustable bewteen 0 and $10 \mathrm{~mA}$. Finally, transistors M3 and M6 compensate the $\mathrm{V}_{\mathrm{DS}}$ drop across transistors M1,M2 and M4,M5, respectively. 


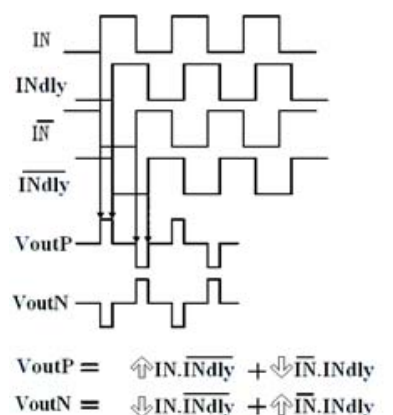

Fig. 6: Pre-emphasis waveforms and transfer function

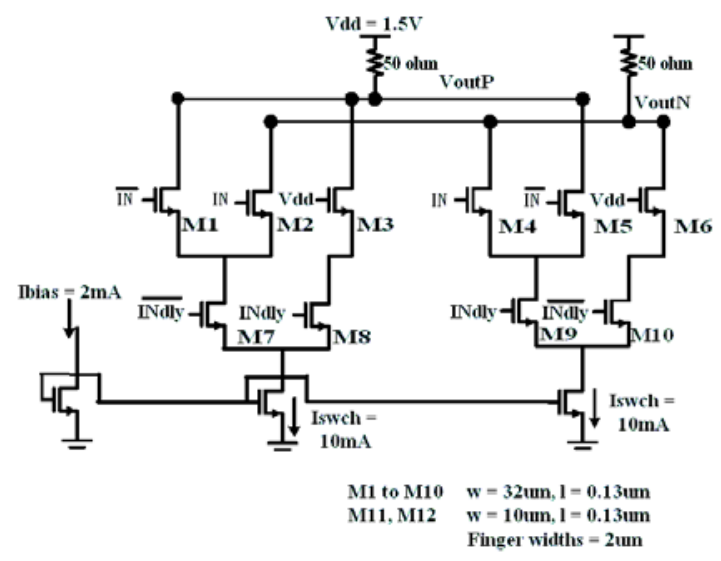

Fig. 7: NMOS Digital differentiator

Fabrication

The circuit was fabricated in STMicroelectronics' 130 $\mathrm{nm}$ standard CMOS process with typical n-MOSFET $\mathrm{f}_{\mathrm{T}}$ and $\mathrm{f}_{\max }$. of $90 \mathrm{GHz}$ and $100 \mathrm{GHz}$, respectively. The chip microphotograph is reproduced in Fig. 8. The design is pad-limited and the area of the design around the outside of the pads is $1.0 \mathrm{~mm} \times 0.5 \mathrm{~mm}$. Power and ground signals were placed along the central horizontal line. Transistors and poly-silicon resistors are located adjacent to the central line, followed by signal path routing, and with the load inductors on the outside. Each of the 18 inductors was implemented with 3-D stacked-spiral layouts and the area occupied by each inductor is less than $40 \mu \mathrm{m} \times 40 \mu \mathrm{m}$.

\section{Experimental Results}

The circuit was fully tested on wafer. The small signal $S$ parameters and noise figure were measured in a singleended configuration. The input and output return loss is better than $-12 \mathrm{~dB}$ up to $50 \mathrm{GHz}$, as shown in Fig. 9. The differential small signal gain was be $18 \mathrm{~dB}$, also confirmed in large by the eye diagram measurements of Fig. 10. The single-ended noise figure is $16 \mathrm{~dB}, 2-\mathrm{dB}$ higher than simulation.

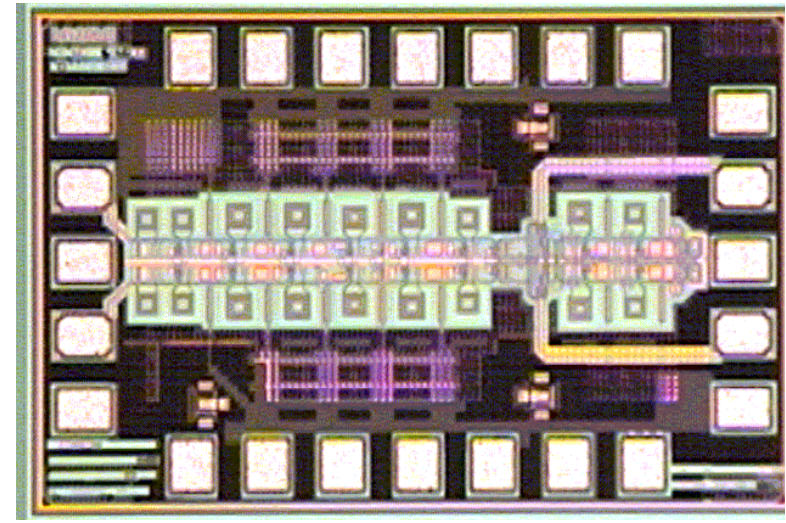

Fig. 8: Chip Photograph

Time domain measurements were performed with an Anritsu $40 \mathrm{~Gb} / \mathrm{s}$ BERT specified between $25 \mathrm{~Gb} / \mathrm{s}$ and 43 $\mathrm{Gb} / \mathrm{s}$ and a PRBS pattern of $2^{31}-1$. At $20 \mathrm{~Gb} / \mathrm{s}$ the BERT operates out of range with significantly more jitter than at $25 \mathrm{~Gb} / \mathrm{s}$ or $30 \mathrm{~Gb} / \mathrm{s}$. A sensitivity of 20 $\mathrm{mVpp}$, as illustrated in Fig. 10, was measured at $20 \mathrm{~Gb} / \mathrm{s}$ when the input was applied single-endedly and the unused input was terminated with a $50-\Omega$ load. The sensitivity degraded to $60 \mathrm{mVp}-\mathrm{p}$, and $150 \mathrm{mVpp}$, at $25 \mathrm{~Gb} /$ $\mathrm{s}$ and $30 \mathrm{~Gb} / \mathrm{s}$, respectively.

Typical $30 \mathrm{~Gb} / \mathrm{s}$ and $25 \mathrm{~Gb} / \mathrm{s}$ output eye diagrams are illustrated in Figs. 11 and 12, respectively. Fig. 13 demonstrate $40 \%$ to $60 \%$ eye-crossing control at $25 \mathrm{~Gb} / \mathrm{s}$.

Fig. 14 shows output amplitude control at $20 \mathrm{~Gb} / \mathrm{s}$. The input signal in both diagrams is $200 \mathrm{mVpp}$, applied to one side only, and the output is varied between $170 \mathrm{mVpp}$ and $340 \mathrm{mVpp}$. The measured waveforms with pre-emphasis at 20Gb/s are reproduced in Fig. 15. The eye-diagram exhibits higher positive overshoot than undershoot. Table 1 summarizes the overall circuit characteristics.

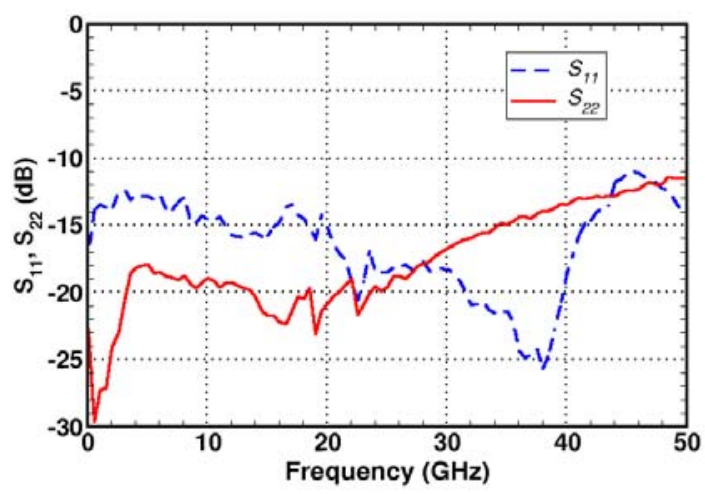

Fig. 9: Measured single-ended $S_{22}$ and $S_{11}$ 


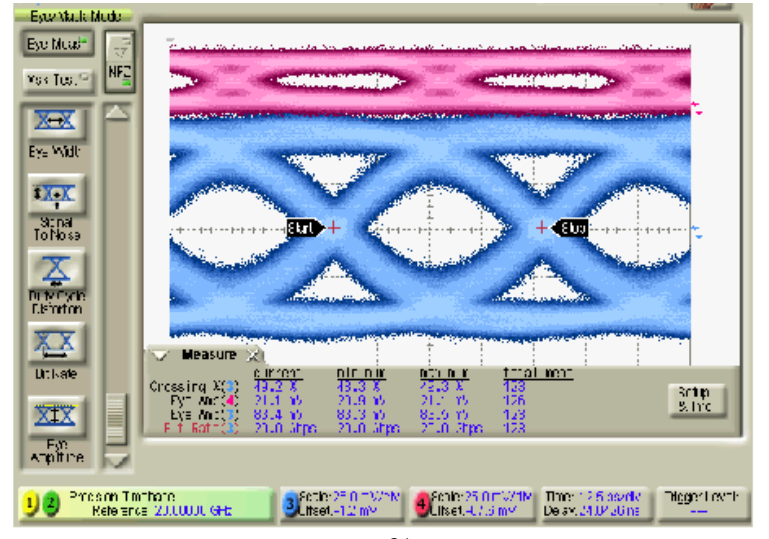

Fig. 10: 20Gb/s eye-diagrams $2^{31}-1$ PRBS: single-ended input $21 \mathrm{mVpp}$, differential output $84 \mathrm{mVpp}$ per side

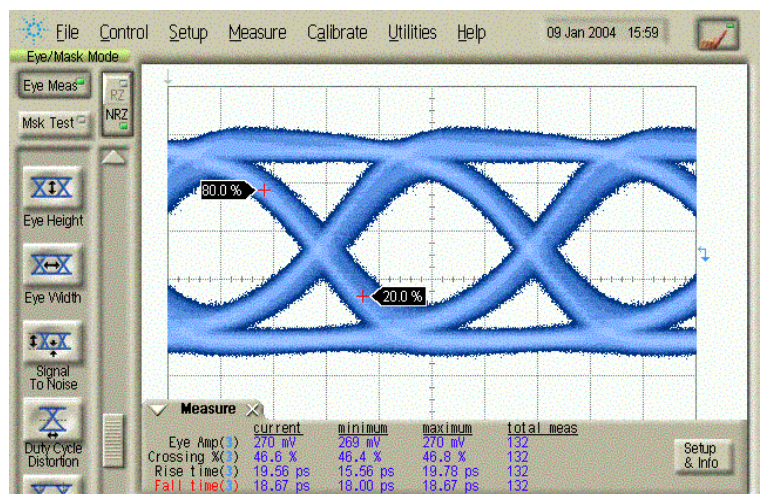

Fig. 11: $30 \mathrm{~Gb} / \mathrm{s}$ output eye-diagram with $260 \mathrm{mVpp}$ per side for a single-ended $200 \mathrm{mVpp}, 2^{31}-1$ input PRBS.

\section{Conclusions}

A $20 \mathrm{~Gb} / \mathrm{s}$ backplane driver with more than $30 \mathrm{~dB}$ dynamic range was implemented in 130-nm CMOS technology. The circuit consumes $150 \mathrm{~mW}$ from a $1.5 \mathrm{~V}$ supply and features output swing, duty cycle and preemphasis control. The circuit is operational without preemphasis at data rates up to $30 \mathrm{~Gb} / \mathrm{s}$ with $300 \mathrm{mVp}$-p swing per side.

Acknowedgments: We thank Rudy Beerkens and Steve McDowall of STMicroelectronics for their support, and STMicroelectronics for chip fabrication, access to test equipment, and for design support.

\section{References}

[1] S. Galal, B. Razavi, "40Gb/s Amplifier and ESD protection Circuit in 0.18-um CMOS Technology," IEEE ISSCC Digest, pp.480-481, 2004

[2] D. Kehrer, H.D. Wohlmuth, " $40 \mathrm{~Gb} / \mathrm{s}$ 2:1 Multiplexer and 1:2 Demultiplexer in $120 \mathrm{~nm}$ CMOS," IEEE ISSCC Digest, pp. 345-346, 2003

[3] D.S. McPherson et al., JSSC, Vol.9, pp.1485-1496, 2003.

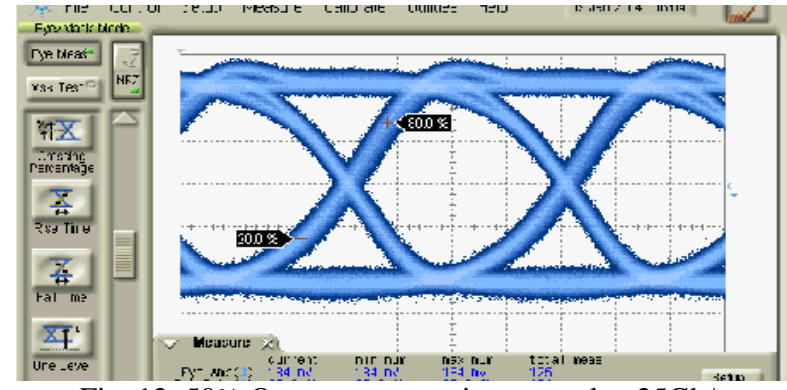

Fig. 12: $50 \%$ Output eye-crossing control at $25 \mathrm{~Gb} / \mathrm{s}$

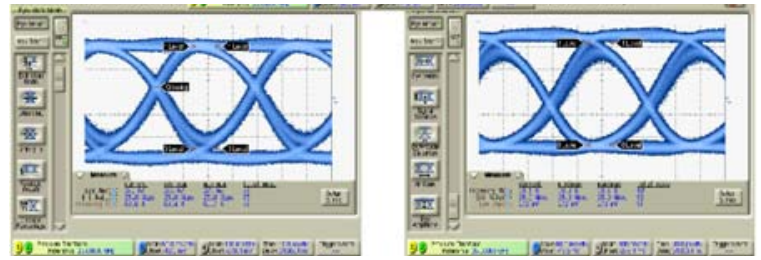

Fig. 13: $40 \%-60 \%$ output eye-crossing control at $25 \mathrm{~Gb} / \mathrm{s}$
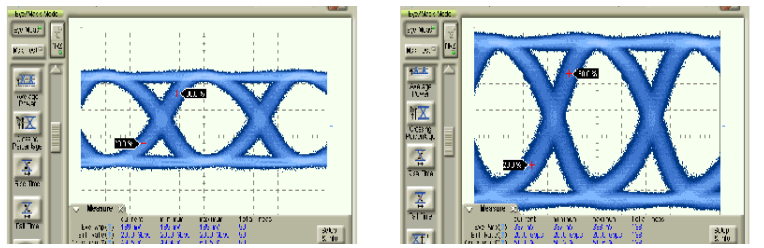

Fig. 14: Output amplitude control at $20 \mathrm{~Gb} / \mathrm{s}$ : output of $170 \mathrm{mVpp}$ and $340 \mathrm{mVpp}$ per side, respectively.

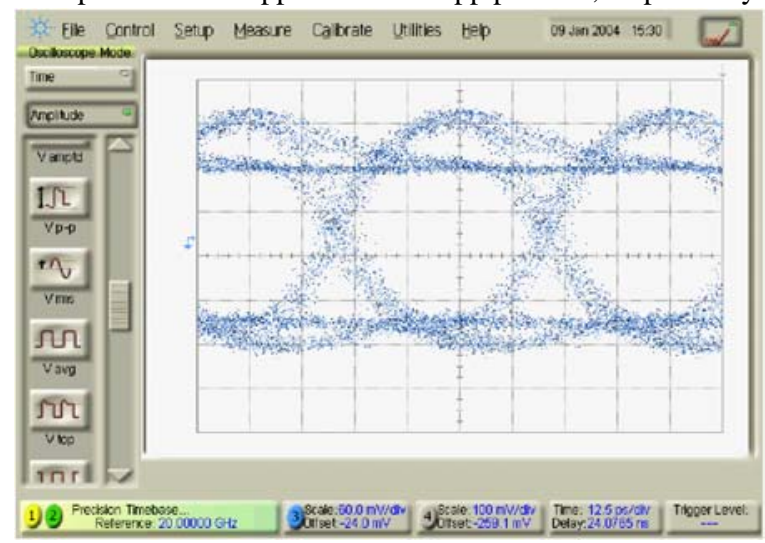

Fig. 15: $20 \mathrm{~Gb} / \mathrm{s}$ output eye diagram with $300 \mathrm{mVpp}$ swing per side and pre-emphasis.

Table 1: Measured Circuit Parameters

\begin{tabular}{|l|l|}
\hline Parameter & Measured value \\
\hline supply & $1.5 \mathrm{~V}$ \\
\hline Power & $150 \mathrm{~mW}$ \\
\hline Output Swing $@ 20 \mathrm{Gbps}$ & $170-350 \mathrm{mVpp}$ \\
\hline Pre-emphasis Control $a 20 \mathrm{Gbps}$ & $30 \%$ \\
\hline Crossing Control $@ 20 \mathrm{Gbps}$ & $30 \%$ to $70 \%$ \\
\hline Eye sensitivity $a 20 \mathrm{Gbps}$ & $20(10) \mathrm{mVpp}$ \\
\hline Noise Figure & $16 \mathrm{~dB}$ \\
\hline S11/S22 up to $50 \mathrm{GHz}$ & $<-12 \mathrm{~dB}$ \\
\hline
\end{tabular}


